\title{
Effect of Hydrogen and Strain-Induced Martensite on Mechanical Properties of AISI 304 Stainless Steel
}

\author{
Sang Hwan Bak, Muhammad Ali Abro and Dong Bok Lee * \\ School of Advanced Materials Science and Engineering, Sungkyunkwan University, Suwon 16419, Korea; \\ sanghwan.bak@hanmail.net (S.H.B.); muhammad_aliabro@inbox.com (M.A.A.) \\ * Correspondence: dlee@skku.ac.kr; Tel.: +82-31-290-7355 \\ Academic Editor: Soran Birosca
}

Received: 12 May 2016; Accepted: 16 July 2016; Published: 20 July 2016

\begin{abstract}
Plastic deformation and strain-induced martensite (SIM, $\left.\alpha^{\prime}\right)$ transformation in metastable austenitic AISI 304 stainless steel were investigated through room temperature tensile tests at strain rates ranging from $2 \times 10^{-6}$ to $2 \times 10^{-2} / \mathrm{s}$. The amount of SIM was measured on the fractured tensile specimens using a feritscope and magnetic force microscope. Elongation to fracture, tensile strength, hardness, and the amount of SIM increased with decreasing the strain rate. The strain-rate dependence of RT tensile properties was observed to be related to the amount of SIM. Specifically, SIM formed during tensile tests was beneficial in increasing the elongation to fracture, hardness, and tensile strength. Hydrogen suppressed the SIM formation, leading to hydrogen softening and localized brittle fracture.
\end{abstract}

Keywords: stainless steel; hydrogen embrittlement; strain-induced martensite; magnetic force microscopy

\section{Introduction}

Metastable austenitic stainless steel belongs to transformation-induced plasticity (TRIP) steel, which has high strength and good ductility owing to the formation of strain-induced martensite $\left(\mathrm{SIM}, \alpha^{\prime}\right)$ [1-5]. This, however, leads to hydrogen embrittlement (HE), limiting the application of austenitic stainless steel such as AISI 301, 304, and 316 in hydrogen-containing environments since SIM acts as a diffusion path of hydrogen [6,7]. HE depends on many factors such as the composition, temperature, residual stress, microstructure, and surface condition of steels. To explain the effect of hydrogen on the mechanical properties of steel, mechanisms such as internal pressure [8-11], surface energy [12], decohesion [13], hydrogen-enhanced plasticity [14], and hydrogen-enhanced strain-induced vacancies [15-17] have been proposed. However, HE has not yet been fully clarified due to the following uncertainties: firstly, why SIM increases the ductility of austenitic stainless steel, and secondly, why hydrogen suppresses the SIM formation in H-charged austenitic stainless steel. In this study, room-temperature (RT) tensile tests were conducted on bare and H-charged AISI 304 at the strain rate of $2 \times 10^{-6} / \mathrm{s}-2 \times 10^{-2} / \mathrm{s}$ in order to clarify the first uncertainty. To clarify the second uncertainty, SIM was measured in situ for bare and H-charged AISI 304 during RT tensile tests, and the volume fraction and distribution of SIM were measured for AISI 304 deformed to the same strain. The aim of this study is to correlate the amount of SIM with mechanical properties, and to correlate the distribution of the SIM formed and the HE with the role of hydrogen in suppressing the SIM formation in AISI 304. 


\section{Materials and Methods}

\subsection{Materials and Hydrogen Charging}

AISI 304 was solution-annealed at $1100{ }^{\circ} \mathrm{C}$ for $1 \mathrm{~h}$ and water quenched. Its chemical composition is listed in Table 1. Its microstructure was examined by optical microscopy. After etching with 8:1:1 vol. ratio of $\mathrm{H}_{2} \mathrm{O}: \mathrm{HF}: \mathrm{HNO}_{3}$ solution for $5 \mathrm{~min}$, its grain size was determined using intercept measurement. Hydrogen was charged through electrolytic charging at $80^{\circ} \mathrm{C}$ with the current density of $500 \mathrm{~A} / \mathrm{m}^{2}$ for $20 \mathrm{~h}$ in $1 \mathrm{~N} \mathrm{H}_{2} \mathrm{SO}_{4}$ solution containing $0.25 \mathrm{~g} / \mathrm{L} \mathrm{NaAsO}_{2}$. The amount of hydrogen charged to the AISI 304 was analyzed with a hydrogen analyzer for two different samples.

Table 1. Chemical composition of AISI 304 stainless steels (wt. \%).

\begin{tabular}{cccccccccccc}
\hline $\mathbf{F e}$ & $\mathbf{C r}$ & $\mathbf{N i}$ & $\mathbf{M n}$ & $\mathbf{S i}$ & $\mathbf{C u}$ & $\mathbf{C o}$ & $\mathbf{M o}$ & $\mathbf{N}$ & $\mathbf{C}$ & $\mathbf{S}$ & $\mathbf{P}$ \\
\hline Bal. & 18.17 & 8.03 & 1.04 & 0.46 & 0.18 & 0.12 & 0.11 & 0.047 & 0.043 & 0.04 & 0.001 \\
\hline
\end{tabular}

\subsection{Determination of the Amount of Strain-Induced Martensite (SIM) and Tensile Testing Procedure}

RT tensile tests were conducted at strain rates varying from $2 \times 10^{-6} / \mathrm{s}$ to $2 \times 10^{-2} / \mathrm{s}$ on bare and H-charged AISI 304 immediately after hydrogen charging. The rod-shaped samples were $4 \mathrm{~mm}$ in diameter with a gauge length of $25.4 \mathrm{~mm}$. Tensile tests were performed twice to get the average value. The amount of SIM was measured in situ for bare and H-charged samples during RT tensile testing using a feritscope (Fisher MP30, Aberdeenshire, Scotland). The values measured by the feritscope agreed well with those measured by the magnetic force microscope (MFM, Park systems, Suwon, Korea), when considering the dependence of strain rate on the martensite concentration. After calibrating the feritscope using the standard sample, the average amount of the formed SIM was measured either ex situ within $1 \mathrm{~mm}$ of the fracture surface five times, or in situ at the center of the gauge section during tensile testing. For the sample deformed to the same strain, the volume fraction and distribution of SIM on the surface were measured using the MFM by applying the distinct magnetic properties of nonmagnetic austenite $(\gamma)$ and ferromagnetic $\alpha^{\prime}$ [17-19]. Images of MFM and atomic force microscope (AFM, Park systems, Suwon, Korea) were obtained in air using a scanning probe microscope (Nanoscope IIIa) in the tapping/lift mode with a lift height of $100 \mathrm{~nm}$.

\section{Results and Discussion}

\subsection{Hydrogen Diffusion in AISI 304}

Figure 1 shows an optical microstructure of the H-charged sample. The mean grain size of $67 \pm 5 \mu \mathrm{m}$ was finer than other reported sizes $(80-150 \mu \mathrm{m})[20,21]$. Hydrogen charging did not change the microstructure. The average amount of hydrogen immediately after H-charging was $51 \pm 5 \mathrm{ppm}$, which was smaller than the 80-110 ppm reported under similar charging conditions [22,23]. This was due to the finer mean grain size, i.e., hydrogen discharging out of the surface increased with the increasing density of the grain boundaries [24]. It is also worth noting that the mean grain size of a few tens of microns enhanced the hydrogen diffusion along the grain boundaries by several orders of magnitude [25]. 


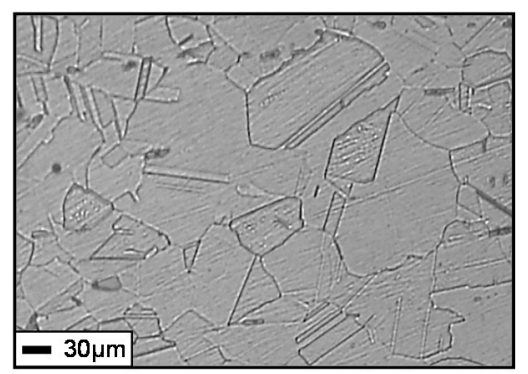

Figure 1. Optical microstructure of H-charged AISI 304 (etched).

Hydrogen was generally confined to the surface during charging. The hydrogen diffusion coefficient, $D$, was $4.0 \times 10^{-15} \mathrm{~m}^{2} / \mathrm{s}$ at the hydrogen-charging temperature of $80{ }^{\circ} \mathrm{C}$ [26]. The penetration depth of hydrogen, $d$, can be roughly expressed by $d=\sqrt{2 D t}$, where $t$ is the charging time (h). It was about $24 \mu \mathrm{m}$, implying that hydrogen was present only around the surface. However, brittle facture occurred not only around the surface but also inside the sample where hydrogen was free, as will be explained later.

\subsection{Hydrogen Effect on Mechanical Property}

The mechanical property strongly depended on the strain rate and hydrogen, as shown in Figure 2. $\mathrm{H}$-free AISI 304 displayed a negative strain rate sensitivity in that the increment of the strain rate led to the decrement of the tensile strength, elongation to fracture, and hardness. Its yield stress, however, decreased at the slowest strain rate of $2 \times 10^{-6} / \mathrm{s}$. The hydrogen effect varied, depending on the strain rate. The $\mathrm{H}$-charging decreased the tensile strength, elongation to fracture, and hardness, but increased the yield stress to a small extent except at the slowest strain rate.
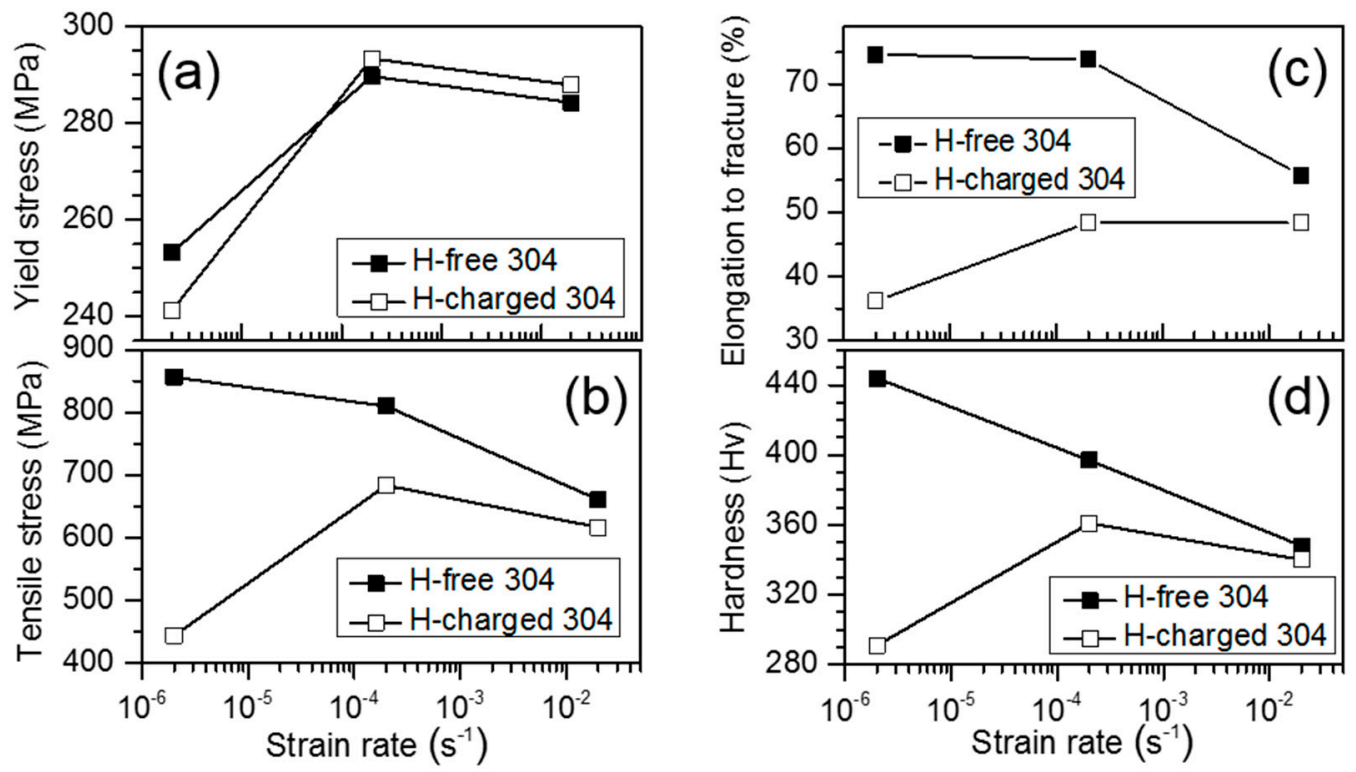

Figure 2. Mechanical properties of H-free and H-charged AISI 304 as a function of strain rate: (a) yield stress; (b) tensile strength; (c) elongation to fracture; (d) Vickers microhardness.

Figure 3 shows the fracture surfaces of $\mathrm{H}$-free and H-charged AISI 304 after RT tensile tests. $\mathrm{H}$-free samples displayed uniform ductile fracture with fine dimples at all strain rates (Figure 3a,b). In contrast, $\mathrm{H}$-charged samples changed the fracture mode from ductile fracture with localized shear dimples at the strain rate of $2 \times 10^{-2} / \mathrm{s}$ (Figure 3c) to enhanced localized brittle fracture in a rectilinear shape parallel to each other at the strain rates of $2 \times 10^{-4} / \mathrm{s}$ and $2 \times 10^{-6} / \mathrm{s}$ (Figure $3 \mathrm{~d}$ ). The localized 
brittle fracture became more pronounced with decreasing the strain rate. Especially in Figure 3d, cracks developed around the boundary between the localized brittle fracture region and the ductile fracture region with dimples. Clearly, hydrogen induced localized brittle fracture in the H-charged AISI 304. Since SIM increased the elongation to fracture (Figure 2) and H-free samples displayed a uniform ductile fracture with fine dimples irrespective of the strain rates (Figure $3 a, b$ ), the $\gamma-\alpha$ transformation was proposed to suppress the formation of the localized brittle deformation. A similar mechanism was proposed to explain the enhanced elongation to fracture of the TRIP steel [5]. Since SIM delayed the formation of necking through the $\gamma$ - $\alpha$ transformation during plastic deformation $[3,5,27,28]$, the localized brittle fracture might be controlled by the $\gamma-\alpha$ transformation, which increased ductility.
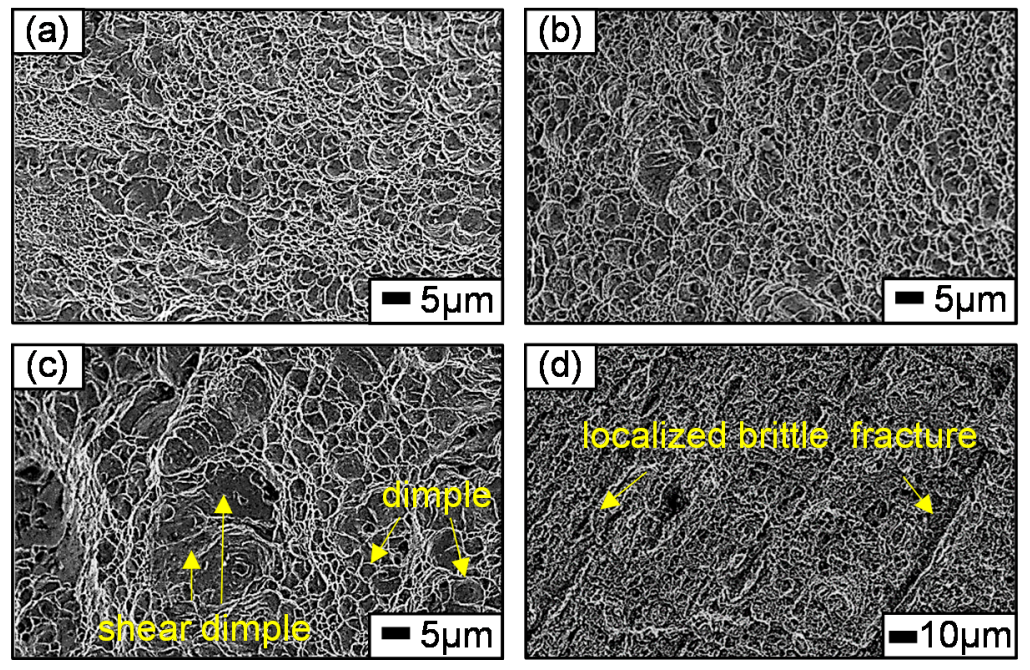

Figure 3. Fracture surfaces of AISI 304 after tensile test: (a) H-free (strain rate $=2 \times 10^{-2} / \mathrm{s}$ ); (b) H-free (strain rate $\left.=2 \times 10^{-6} / \mathrm{s}\right) ;\left(\right.$ c) H-charged (strain rate $=2 \times 10^{-2} / \mathrm{s}$ ); (d) H-charged (strain rate $=2 \times 10^{-6} / \mathrm{s}$ ).

\subsection{Hydrogen Effect on Formation of SIM}

Figure 4 shows the amount of SIM that formed on the fracture surface at different strain rates for $\mathrm{H}$-free and H-charged AISI 304. The amount of SIM that formed on the surface increased in the H-free sample, but decreased in the $\mathrm{H}$-charged sample, with decreasing the strain rate. The H-free sample had a larger amount of SIM than the H-charged sample at the same strain rate. The amount of SIM was the smallest in the H-charged sample at the slowest strain rate of $2 \times 10^{-6} / \mathrm{s}$. This suggested that hydrogen suppressed the SIM formation during tensile testing, which became more pronounced with decreasing the strain rate.

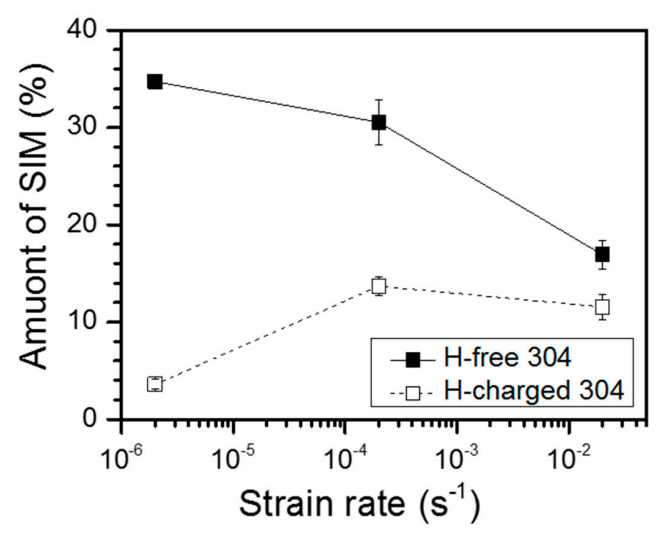

Figure 4. Amount of SIM as a function of the strain rate for H-free and H-charged AISI 304 after tensile tests. 
To confirm the above suggestion, SIM was measured in situ for $\mathrm{H}$-free and $\mathrm{H}$-charged samples at the strain rate of $2 \times 10^{-4} / \mathrm{s}$ using the feritscope. Figure 5 indicates that the amount of SIM was decided by the plastic deformation and hydrogen. Hydrogen charging decreased the amount of SIM during the plastic deformation, displaying the largest decrement at the strain of $35 \%-45 \%$.

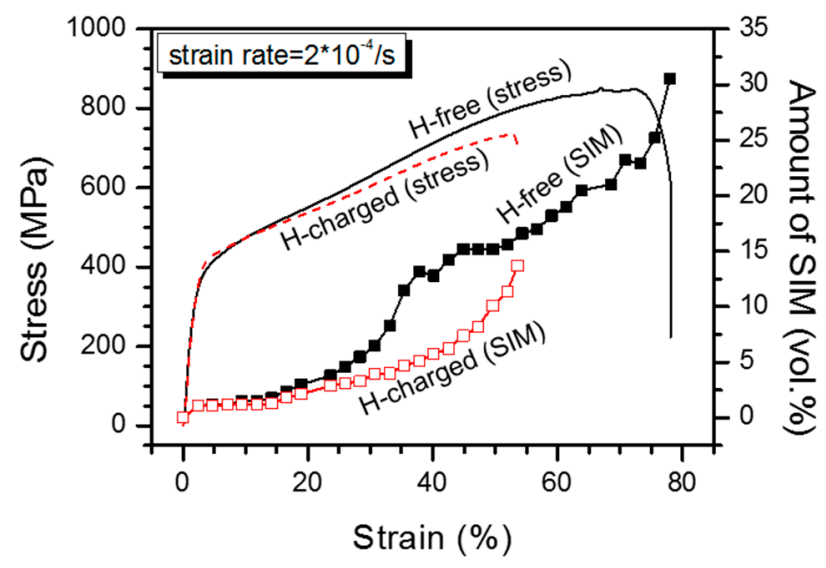

Figure 5. Stress (solid and dotted lines) and the amount of SIM formed (enclosed and open circles) as a function of strain for H-free and H-charged AISI 304. Strain rate $=2 \times 10^{-4} / \mathrm{s}$.

In order to validate that hydrogen suppressed SIM formation at the same plastic strain, the volume fraction and distribution of SIM in H-free and H-charged AISI 304 were examined before and after tensile tests using MFM and the image analyzer, as shown in Figure 6. Dark and light phases corresponded to martensite $\left(\alpha^{\prime}\right)$ and austenite $(\gamma)$, respectively, in the MFM images that were taken at $2.5 \mathrm{~mm}$ apart from the fracture surface. They were more distinct in the image analyzer images. The average amount of SIM was 1.5\%, whereas SIM aligned along the tensile axis, tens to hundreds of micrometers apart, before tensile testing (Figure 6a). It increased with increasing the strain, regardless of the presence of hydrogen. In Figure $6 \mathrm{~b}, \mathrm{c}$, SIM distributed non-uniformly in a ribbon shape several hundred micrometers in width. At $45 \%$ plastic strain, the $\mathrm{H}$-free sample had more SIM than the H-charged one. Figures 5 and 6 suggested that hydrogen suppressed SIM formation during tensile testing. This was plausible considering the ductility loss and the beneficial effects of SIM on the mechanical property of the H-free samples. In addition, the localized brittle fracture became more pronounced with decreasing the strain rate in the H-charged sample (Figure 3). This was related to the decreased amount of SIM that formed during tensile deformation. As will be explained below, the decrement of the microhardness owing to the hydrogen softening in the H-charged sample provided further evidence for the suppression of SIM formation by hydrogen.

The relationship between the amount of SIM and the mechanical property is depicted in Figure 7. The elongation to fracture, tensile strength, and microhardness of $\mathrm{H}$-free and $\mathrm{H}$-charged AISI 304 positively depended on the amount of SIM that formed during RT tensile testing. SIM beneficially increased elongation to fracture, tensile strength, and hardness, with and without hydrogen. This was also consistent with the TRIP effect, which increased elongation to fracture and tensile strength through the deformation-induced martensite transformation [3-5]. Tensile properties of the H-free samples depended on the strain rate, as shown in Figures 2 and 7. This was also related to the amount of SIM formed during plastic deformation. However, the hardness of the $\mathrm{H}$-free sample increased with increasing the amount of SIM (Figure 2d). This implied that SIM was harder than austenite [27]. The cause of the dependence of the strain rate on the amount of SIM formed in austenitic stainless steel, as shown in Figure 4, was still unresolved. The reason for the enhancement of elongation to fracture by the hard SIM was also unclarified. In Figure 7, H-charged samples showed more sensitive linear dependence than $\mathrm{H}$-free samples, implying that the suppression of SIM formation by hydrogen had a decisive effect on the mechanical property. The dependence of mechanical properties on the amount 
of SIM (Figure 7) and the suppression of SIM formation by hydrogen (Figures 5 and 6) indicated that hydrogen decreased the amount of SIM formed during tensile testing, which led to the loss of elongation to fracture and tensile strength. Hence, the hydrogen embrittlement and softening were inevitable in the H-charged samples.
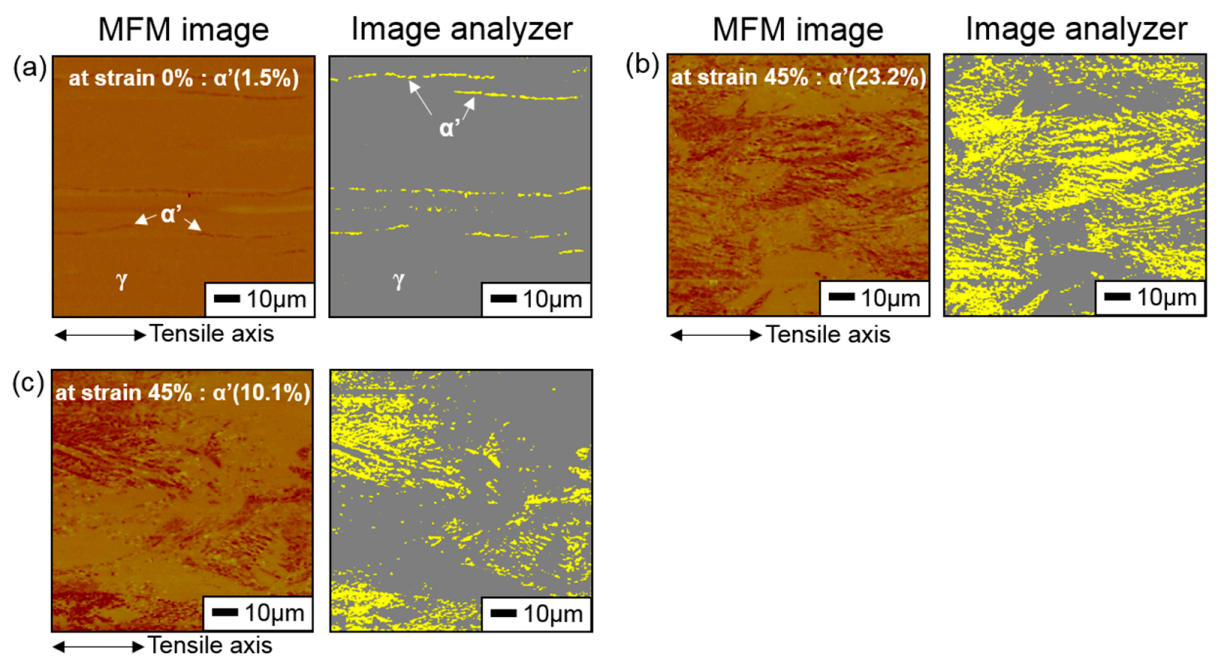

Figure 6. Distribution of austenite and martensite in AISI 304: (a) before tensile test (strain $=0 \%$ ); (b) $\mathrm{H}$-free (strain $=45 \%$ ) at the strain rate of $2 \times 10^{-4} / \mathrm{s}$; (c) H-charged (strain $=45 \%$ ) at the strain rate of $2 \times 10^{-4} / \mathrm{s}$.

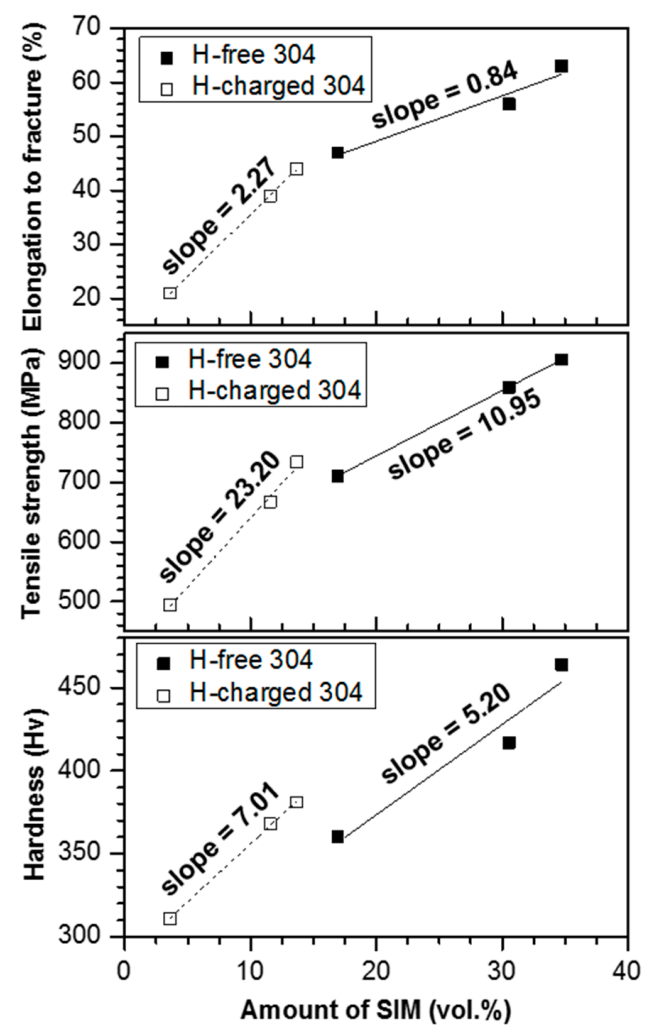

Figure 7. Linear dependence of mechanical properties on the amount SIM formed in H-free and H-charged AISI 304 during tensile testing: (a) elongation to fracture; (b) tensile strength; (c) microhardness. 


\section{Conclusions}

The plastic deformation behavior and strain-induced martensite transformation were investigated through tensile testing AISI 304 metastable austenitic stainless steel at a slow strain rate at room temperature. The H-free AISI 304 showed a decreased yield stress and increased elongation to fracture and tensile strength with decreasing the strain rate. The strain-rate dependence of the tensile properties of H-free AISI 304 was closely related to the amount of SIM. In contrast, in H-charged samples, hydrogen decreased the yield stress slightly, but tensile strength and elongation to fracture significantly at all strain rates. However, the loss in tensile strength and elongation to fracture by hydrogen in H-charged samples showed strong strain-rate dependence. Considering the beneficial role of SIM in the tensile properties of H-free AISI 304, the ductility loss and hydrogen softening in the hydrogen-charged samples were related to the suppressed SIM formation by hydrogen. This suppression by hydrogen was considered as the main cause of hydrogen embrittlement and hydrogen softening in austenitic stainless steels.

Acknowledgments: This work was supported by the Human Resource Development Program (No. 20134030200360) of the Korea Institute of Energy Technology Evaluation and Planning (KETEP) grant funded by the Korea government Ministry of Trade, Industry and Energy.

Author Contributions: Sang Hwan Bak and Dong Bok Lee conceived and designed the experiments; Sang Hwan Bak performed the experiments and wrote the paper. Muhammad Ali Abro helped the discussion. Dong Bok Lee reviewed and contributed to the final manuscript.

Conflicts of Interest: The authors declare no conflict of interest.

\section{References}

1. Antolovich, S.D.; Fahr, D. An experimental investigation of the fracture characteristics of TRIP alloys. Eng. Fract. Mech. 1972, 4, 133-144. [CrossRef]

2. Perdahcıoğlu, E.S.; Geijselaers, H.J.M.; Groen, M. Influence of plastic strain on deformation-induced martensitic transformations. Scr. Mater. 2008, 58, 947-950. [CrossRef]

3. Hwang, J.; Son, I.; Yoo, J.; Zargaran, A.; Kim, N. Effect of reduction of area on microstructure and mechanical properties of twinning-induced plasticity steel during wire drawing. Met. Mater. Int. 2015, 21, 815-822. [CrossRef]

4. Oliver, E.C.; Withers, P.J.; Daymond, M.R.; Ueta, S.; Mori, T. Neutron-diffraction study of stress-induced martensitic transformation in TRIP steel. Appl. Phys. A 2002, 74, S1143-S1145. [CrossRef]

5. Tamura, I. Deformation-induced martensitic transformation and transformation-induced plasticity in steels. Met. Sci. 1982, 16, 245-253. [CrossRef]

6. Briant, C.L. Hydrogen assisted cracking of type 304 stainless steel. Metall. Trans. A 1979, 10, 181-189. [CrossRef]

7. Hanninen, H.; Hakkarainen, H. On the effects of $\alpha^{\prime}$ martensite in hydrogen embrittlement of a cathodically charged AISI type 304 austenitic stainless steel. Corrosion 1980, 36, 47-51. [CrossRef]

8. Zapffe, C.A.; Sims, C.E. Hydrogen embrittlement internal stress and defects in steels. Trans. Am. Inst. Min. Eng. 1941, 145, 225-259.

9. Garofalo, F.; Chou, Y.T.; Ambegaokar, V. Effect of hydrogen on stability of micro cracks in iron and steel. Acta Metall. 1960, 8, 504-512. [CrossRef]

10. Bilby, B.A.; Hewitt, J. Hydrogen in steel-The stability of micro-cracks. Acta Metall. 1962, 10, 587-600. [CrossRef]

11. Escobar, D.P.; Miñambres, C.; Duprez, L.; Verbeken, K.; Verhaege, M. Internal and surface damage of multiphase steels and pure iron after electrochemical hydrogen charging. Corros. Sci. 2011, 53, 3166-3176. [CrossRef]

12. Simmons, G.W.; Pao, P.S.; Wei, R.P. Fracture mechanics and surface chemistry studies of subcritical crack growth in AISI 4340 steel. Metall. Trans. A 1978, 9, 1147-1158. [CrossRef]

13. Takano, N. First principles calculation of hydrogen embrittlement in iron. Key Eng. Mater. 2010, 417-418, 285-288. [CrossRef] 
14. Birnbaum, H.K.; Sofronis, P. Hydrogen-enhanced localized plasticity-A mechanism for hydrogen-related fracture. Mater. Sci. Eng. A 1994, 176, 191-202. [CrossRef]

15. Takai, K.; Shoda, H.; Suzuki, H.; Nagumo, M. Lattice defects dominating hydrogen-related failure of metals. Acta Mater. 2008, 56, 5158-5167. [CrossRef]

16. Nagumo, M. Hydrogen related failure of steels-A new aspect. Mater. Sci. Technol. 2004, 20, 940-950. [CrossRef]

17. Zhang, L.; An, B.; Fukuyama, S.; Iijima, T.; Yokogawa, K. Characterization of hydrogen-induced crack initiation in metastable austenitic stainless steels during deformation. J. Appl. Phys. 2010, 108, 0635226. [CrossRef]

18. Miller, A.; Estrin, Y.; Hu, X.Z. Magnetic force microscopy of fatigue crack tip region in a 316L austenitic stainless steel. Scr. Mater. 2002, 47, 441-446. [CrossRef]

19. Sort, J.; Concustell, A.; Menéndez, E.; Suriñach, S.; Baró, M.D.; Farran, J.; Nogués, J. Selective generation of local ferromagnetism in austenitic stainless steel using nanoindentation. Appl. Phys. Lett. 2006, 89, 032509. [CrossRef]

20. Minkovitz, E.; Eliezer, D. Grain-size and heat-treatment effects in hydrogen-assisted cracking of austenitic stainless steels. J. Mater. Sci. 1982, 17, 3165-3172. [CrossRef]

21. Ralston, K.D.; Birbilis, N. Effect of grain size on corrosion: A review. Corrosion 2006, 66, 075005. [CrossRef]

22. Pan, C.; Chu, W.Y.; Li, Z.B.; Liang, D.T.; Su, Y.J.; Gao, K.W.; Qiao, L.J. Hydrogen embrittlement induced by atomic hydrogen and hydrogen-induced martensites in type 304L stainless steel. Mater. Sci. Eng. A 2003, 351, 293-298. [CrossRef]

23. Au, M. High temperature electrochemical charging of hydrogen and its application in hydrogen embrittlement research. Mater. Sci. Eng. A 2007, 454-455, 564-569. [CrossRef]

24. Yao, J.; Cahoon, J.R. Experimental studies of grain boundary diffusion of hydrogen in metals. Acta. Metall. Mater. 1991, 39, 119-126. [CrossRef]

25. Oudriss, A.; Creus, J.; Bouhattate, J.; Savall, C.; Peraudeau, B.; Feaugas, X. The diffusion and trapping of hydrogen along the grain boundaries in polycrystalline nickel. Scr. Mater. 2012, 66, 37-40. [CrossRef]

26. Austin, J.H.; Elleman, T.S.; Verghese, K. Surface effects on the diffusion of tritium in 304-stainless steel and zircaloy-2. J. Nucl. Mater. 1973, 48, 307-316. [CrossRef]

27. Mine, Y.; Horita, Z.; Murakami, Y. Effect of hydrogen on martensite formation in austenitic stainless steels in high-pressure torsion. Acta Mater. 2009, 57, 2993-3002. [CrossRef]

28. Spencer, K.; Embury, J.D.; Conlon, K.T.; Veron, M.; Brechet, Y. Strengthening via the formation of strain-induced martensite in stainless steels. Mater. Sci. Eng. A 2004, 387, 873-881. [CrossRef] 